\title{
The Effect of Vitamin D 3 on the Contractile Response of Isolated Rat Uterus
}

\author{
EMAN R. ABOZAID, M.D.* and HANY A. EL KATTAWY, M.D.****,*** \\ The Department of Medical Physiology, Faculty of Medicine, Zagazig University*, Obesity Management and Research Unit, \\ Faculty of Medicine, Zagazig University** and Physiology Department, Faculty of Medicine, Almaarefa University, \\ Saudi Arabia***
}

\begin{abstract}
Background: Vitamin D receptors (VDR) are expressed in many reproductive tissues indicating a potential role of vitamin D3-VDR in the regulation of reproductive functions. Nevertheless, the data about the effect of vitamin D 3 in the uterus are scarce.

Aim of Study: This study was designed to evaluate the potential effects of vitamin D 3 on spontaneous, $\mathrm{KCl}$-induced and oxytocin-induced contractions in the rat uterus in vitro.

Material and Methods: The study was conducted on 10 healthy adult female albino non-pregnant rats. Full-thickness longitudinal muscle strips were dissected from each nonpregnant rat and then myometrial tension was recorded. The strips were mounted vertically in organ baths and exposed to vitamin D3 and different uterotonic agents to delineate the potential action of vitamin D 3 on the rat myometrial contractility. Spontaneous contractions were recorded using mechanical activity recording system. We evaluated the effects of 3 different dosed of vitamin D3 on spontaneous uterine contractions; then on concentrated $\mathrm{KCl}$-induced uterine contractions and oxytocin (OT)-induced uterine contractions. Furthermore, the effects of vitamin D3 on spontaneous uterine contractions pretreated with nifedipine; a voltage-gated L-type $\mathrm{Ca}^{2}{ }^{+}$channel antagonist were investigated.
\end{abstract}

Results: Vitamin D3 significantly inhibited the spontaneous uterine contractions in a dose dependent manner. Moreover, vitamin D3 inhibited the uterine contractions whether induced by oxytocin or concentrated $\mathrm{KCl}$. Administration of nifedipine resulted in a significant decline in the force amplitude of spontaneous uterine contractions. In the presence of vitamin D3, the uterine relaxant effect of nifedipine was significantly augmented.

Conclusions: The inhibitory effects of the in vitro administration of vitamin D 3 on rat uterus may yield novel insights into its therapeutic use. Further, it may be recommended to be used as a novel tocolytic agent for preventing unwanted uterine contractions in early pregnancy and relieving pain related to dysmenorrhea.

Correspondence to: Dr. Eman R. Abozaid, E-Mail: eman.zaher2005@gmail.com
Key Words: Vitamin $D_{3}-$ Oxytocin - Uterus - Contractility.

\section{Introduction}

ADEQUATE and precise uterine contractility is necessary for various reproductive processes, including sperm transport, fruitful embryo transport, implantation, pregnancy and labor [1]; hence, the physiological functions of uterus smooth muscle are essential. The abnormalities of uterine contractility may trigger different clinical defects such as implantation failure, spontaneous miscarriages, infertility, ectopic pregnancies and preterm birth [2-5].

Vitamin D3 is a distinguished steroid and fat soluble compound that regulates bone health predominantly via calcium-phosphorus homeostasis [6]. The biological effects of vitamin D3 are applied via binding to vitamin $\mathrm{D}$ receptors (VDR) which are expressed in many reproductive tissues, therefore, growing evidence indicates that many reproductive functions in human and animals are regulated by vitamin D 3 [7-9]. In female reproductive system, vitamin D 3 may affect various physiological processes in the placenta, ovary and uterus. It is necessary for the normal decidual cells differentiation [10]. Hence, it may contribute to various reproductive pathologies such as endometriosis, uterine fibroids, endometrial carcinoma, preeclampsia and polycystic ovarian syndrome [11-13]. Therefore, little data is available about the exact role of vitamin D 3 and VDR in the uterine tissues and its contribution to the uterine function. There is limited data concerning uterine contractility under the effect of vitamin D3. We hypothesized that vitamin D3 may inhibit the rat uterine contraction in vitro 
and investigated the effects of changing vitamin D3 doses on non-pregnant rat uterine contractility in vitro. Specifically, we studied the effect of vitamin D 3 on spontaneous uterine contractions; uterine contractions induced by oxytocin (OT) and uterine strips depolarized by high concentrations of $\mathrm{KCl}$, in addition to uterine contractility pretreated with nifedipine.

\section{Material and Methods}

\section{Animals and uterine tissue preparation:}

This research was conducted in the scientific and medical research center (ZSMRC) in Faculty of Medicine, Zagazig University in the period from 1 st to 30th of July 2019 and involved 10 healthy non-pregnant adult female albino rats aged 20 weeks, were used in this study. This study protocol was approved by the experimental animal Ethics Committee, Faculty of Medicine, Zagazig University. The experimental procedures were performed in accordance with the guide for the use and care of laboratory animals. The oestrous cycle stages were monitored daily using vaginal smears and the rats were sacrificed only in the metoestrous or dioestrous stages because the uterus produces regular spontaneous contractions in these stages [14]. Additionally, Estradiol was administered 24 $\mathrm{h}$ before decapitation to assist in obtaining a spontaneous periodic contraction of myometrium [15] To get the estrogenized uterus, virgin female rats were subcutaneously injected with 17 - $\beta$-estradiol benzoate $(1 \mathrm{mg} / \mathrm{kg})$ and killed $24 \mathrm{~h}$ later by decapitation. The abdomen was opened longitudinally and the uterus was promptly removed, cleaned of the connective tissue and cut into strips of about $1 \mathrm{~cm}$ of length, then immediately placed in a buffered physiological salt solution (PSS) of the following composition per liter: $9 \mathrm{gm} \mathrm{NaCl}, 420 \mathrm{mg}$ $\mathrm{KCl}, 240 \mathrm{mg} \mathrm{CaCl} 2,0.16 \mathrm{~g} \mathrm{KH}_{2} \mathrm{PO}_{4}, 0.5 \mathrm{~g} \mathrm{NaHCO}_{3}$, $0.5 \mathrm{~g}$ dextrose, $\mathrm{pH} 7.40$ [16]. It was maintained at $37 \pm 0.50^{\circ} \mathrm{C}$ and continuously bubbled with air. The preparation was allowed to equilibrate for $30 \mathrm{~min}$. during which the bathing solution was changed every $10 \mathrm{~min}$.

\section{In vitro contractility study:}

The dissected uterine strips were transferred and mounted vertically in a $5 \mathrm{~mL}$ tissue organ bath (Panlab muti-chambre, ADInstruments Australia), continuously perfused with PSS at a rate of $4 \mathrm{~mL} / \mathrm{min}$ and bubbled with $95 \% \mathrm{O}_{2} / 5 \% \mathrm{CO} 2$ at 37 $8 \mathrm{C}$; the $\mathrm{pH}$ was maintained at 7.40 throughout the experiment [17]. The uterine strips were connected to an isometric force transducer using surgical silk.
Changes in isometric force were recorded, amplified, and displayed using LabChart software. At first, $1 \mathrm{gm}$ of resting tension was applied; the strips were allowed to equilibrate for at least $60 \mathrm{~min}$ to obtain stable and regular uterine contractions [16]

\section{Drugs and chemicals:}

Chemicals for physiologic buffer solution used in this study were purchased from El Gomhouria Co. For Drugs \& Medical Supplies (Egypt). Vitamin D3 (cholecalciferol), oxytocin ( $\alpha$-Hypophamine) and nifedipine (BAY 1040) are obtained from (Sigma Aldrich). All stock solutions were made and stored in accordance with the manufacturer's guidelines. Oxytocin was prepared by dissolving it in distilled water and used at a final working concentration of (10-2IU/mL) [17]. Concentrated $\mathrm{KCl}(60 \mathrm{mM} / \mathrm{L})$ solution was made fresh by isoosmotic replacement of $\mathrm{NaCl}$ [18]. Vitamin D3 was dissolved in ethanol ( $0.1 \%$ in the organ bath) before dilution with the PSS. Nifedipine was kept in a darkened container and dissolved in ethanol.

\section{Experimental protocols:}

Dose-dependent effect of vitamin D 3 on spontaneous uterine contractions:

Three different concentrations of vitamin D 3 $\left(10^{-3}, 10^{-6}, 10^{-9} \mathrm{M}\right)$ were used to find the concentration that produces a $50 \%$ inhibition of $100 \%$ of the force amplitude (IC 50) of uterine strips. Each dose was applied for a period of $10 \mathrm{~min}$, the uterine strips were then washed with physiologic PSS and the recovery of uterine contractions was monitored. The IC 50 was determined and then used throughout the study.

\section{Effects of vitamin D 3 on $\mathrm{KCl}$-induced uterine} contractions:

To investigate the effect of vitamin $\mathrm{D} 3$ on the depolarized uterine strip, $60 \mathrm{mM} \mathrm{KCl}$ was applied twice (each for 10min) to the same uterine strip. Applications of $\mathrm{KCl}$ were done twice separated by a recovery period in physiologic PSS for $10 \mathrm{~min}$. The first $\mathrm{KCl}$ application was applied without vitamin D3 (taken as a 100\% control) and the second application was applied in the presence of vitamin D3.

\section{Effects of vitamin D 3 on oxytocin (OT)-induced} uterine contractions:

Once steady and regular spontaneous contractions were obtained, uterine strips were stimulated with $(10-2 \mathrm{IU} / \mathrm{mL})$ oxytocin for $10 \mathrm{~min}$ to obtain regular phasic contractions (this period was used as a $100 \%$ control). The vitamin D 3 was then added 
for 10min in the continued presence of oxytocin. At the end of experiments, the strip was washed with normal PSS.

Investigations on the calcium (Ca2+) channels involvement:

To test the involvement of calcium channels in the mechanism of action of vitamin $\mathrm{D}_{3}$, nifedipine (Dihydropyridines) which is a $\mathrm{Ca} 2+$ channel antagonist was used. Once steady and regular spontaneous contractions were obtained for 10 minutes (this period was used as a $100 \%$ control). Nifedipine was added with (0.03 for another 10min (The vitamin- $\mathrm{D}_{3}$ was then added for $10 \mathrm{~min}$ in the continued presence of nifedipine. At the end of experiments, the strip was washed with normal PSS.

\section{Data analysis and statistics:}

For each experiment, the results are the means of eight different uterine samples. Data were presented as mean \pm SEM and analyzed using version 24 SPSS program (SPSS Inc. Chicago, IL, USA). Student $t$-test and One way analysis of variance (ANOVA) was used followed by student-least significant differences (LSD) test to compare statistical differences between groups. $p$-value less than 0.05 was considered to be significant. We compare the means of the parameters before and after exposure to vitamin $\mathrm{D}_{3}$ during spontaneous contraction and contraction induced by $\mathrm{KCl}$, oxytocin, in addition to changes accompanying nifedipine. Force amplitude was used as the main parameter to assess the uterine contractile activity, other parameters were measured, such as the frequency (the number of contractions in 10min). The spontaneous contractile activity for the last $10 \mathrm{~min}$ in control solution was calculated as $100 \%$. The 10 -minute vitamin $\mathrm{D}_{3}$ application was analyzed and expressed as a percentage of the preceding control period.

\section{Results}

Vitamin $D_{3}$ dose dependence and its effects on spontaneous uterine contractions:

Cumulative applications of vitamin $\mathrm{D}_{3}$ progressively and significantly inhibited the spontaneous uterine contractions in a dose dependent manner as shown in Table (1), (Fig. 1A, B, C and D).
Application of 10-6 M of vitamin D3 significantly decreased the force amplitude to $50.5 \pm 2.3 \%$. Therefore, 10-6 M of vitamin $\mathrm{D}_{3}$ was taken as the IC 50 and this concentration was used throughout the remainder of the study.

\section{Effects of vitamin $\mathrm{D}_{3}$ on $\mathrm{KCl}$-induced uterine} contraction:

Concentrated $\mathrm{KCl}$ solution increased the uterine force amplitude and it was maintained as long as $\mathrm{KCl}$ was applied; uterine force returned to normal regular contractions when the strip was washed with normal PSS, however, when vitamin $\mathrm{D}_{3}$ was added with the concentrated $\mathrm{KCl}$ solution, the force amplitude significantly declined to $77.2 \% \pm 1.9$ of control values ( $p<0.05, \mathrm{n}=10$, Fig. 2A,2B).

Effects of vitamin $D_{3}$ on Oxytocin $(O T)$-induced uterine contraction:

Application of $10-2 \mathrm{IU} / \mathrm{mL}$ of oxytocin to a spontaneously-contracting uterus caused an increase in the force amplitude and frequency as shown in Fig. (3A). In the presence of vitamin $\mathrm{D}_{3}$, the force amplitude and frequency significantly decreased to $50 \% \pm 4.5$ and $60 \% \pm 3.5$ respectively of control values $(p<0.001, \mathrm{n}=10)$ (Fig. 3B).

Effects of vitamin $D_{3}$ on uterine contraction pretreated with Ca2+ channel antagonist:

Application of 0.03 of nifedipine to a spontaneously-contracting uterus caused a significant decrease in the force amplitude $(51.1 \% \pm 2.3)$ of control value (spontaneous contraction), (Fig. $4 \mathrm{~A}, 4 \mathrm{~B}$ ). In the presence of vitamin $\mathrm{D}_{3}$, the force amplitude significantly decreased to $26 \% \pm 1.1$ of control values $(p<0.001)$.

Table (1): The effect of different concentrations of vitamin $\mathrm{D}_{3}$ on the mean force amplitude of isolated rat uterine preparations (mean $\pm \mathrm{SEM}$ ).

\begin{tabular}{lcc}
\hline Vitamin $\mathrm{D}_{3}(\mathrm{M})$ & Mean force amplitude $(\%)$ & $\mathrm{N}$ \\
\hline $0 /(\mathrm{Control})$ & 100.0000 & 10 \\
$10-3 \mathrm{M}$ & $87.57 \pm 4^{*}$ & 10 \\
$10-6 \mathrm{M}$ & $50.5 \pm 2.3^{* *}$ & 10 \\
$10-9 \mathrm{M}$ & $20.1 \pm 3.1^{* * *}$ & 10 \\
\hline
\end{tabular}

${ }^{*} p<0.05$ compared to the control.

$* * p<0.01$ compared to the control.

$* * * p<0.001$ compared to the control. 
(A)

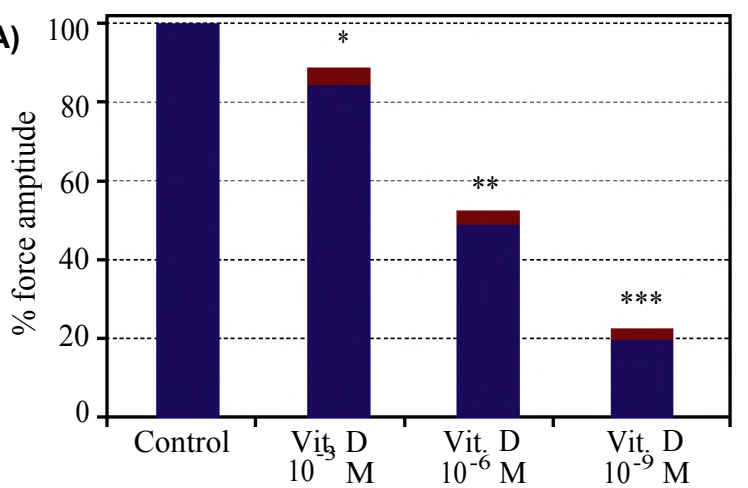

(C)

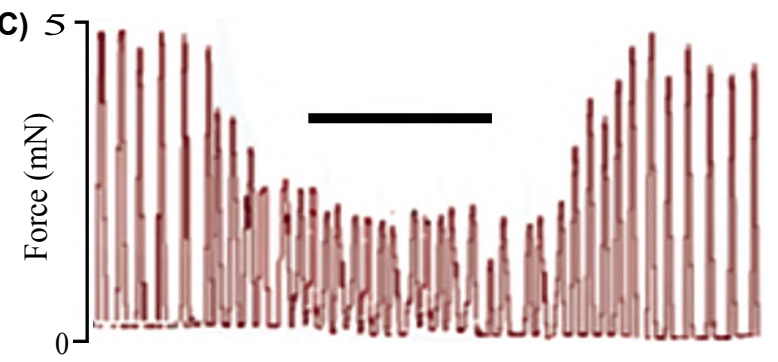

(B)
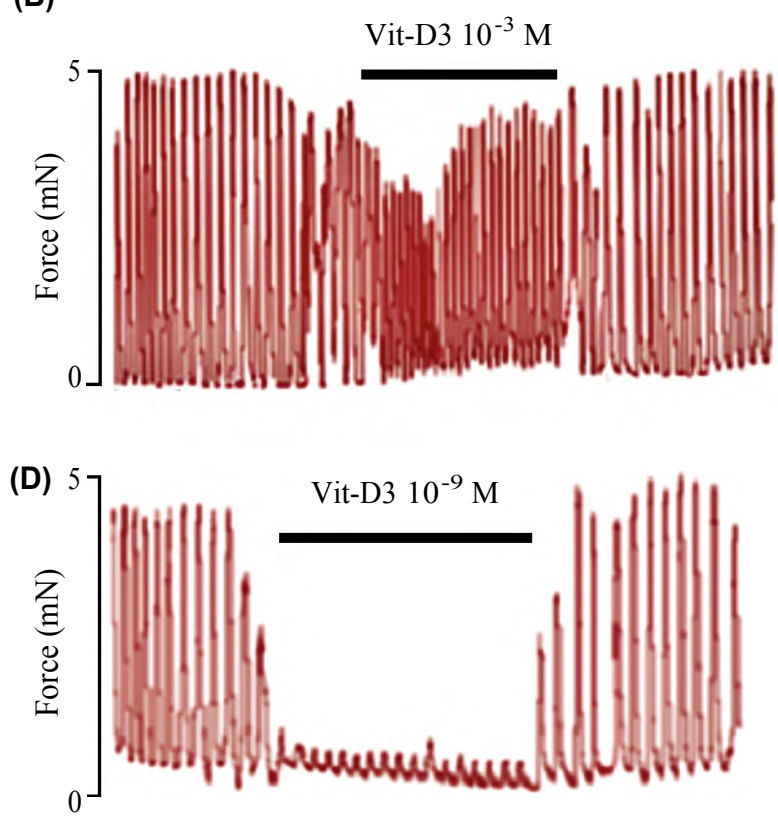

Fig. (1): The effect of different concentrations of vitamin D 3 on rat spontaneous uterine contractions. (A) = Bar chart showing dose dependence decrease of $\%$ force amplitude after increasing concentrations of vit D $3\left(10^{-}, 10^{-6}\right.$, and $\left.10^{-9} \mathrm{M}\right)$, data are the mean \pm SEM of 10 independent samples, ${ }^{*} p<0.05$, ${ }^{* *} p<0.01$, and $* * * p<0.001$. (B) The effect of $10^{-3} \mathrm{M}$ (C) $10^{-6} \mathrm{M}$, and (D) 10_9 $\mathrm{M}$ of vitamin D3 on spontaneous contractions of isolated non-pregnant estrogenized rat uterine preparations.

(A)

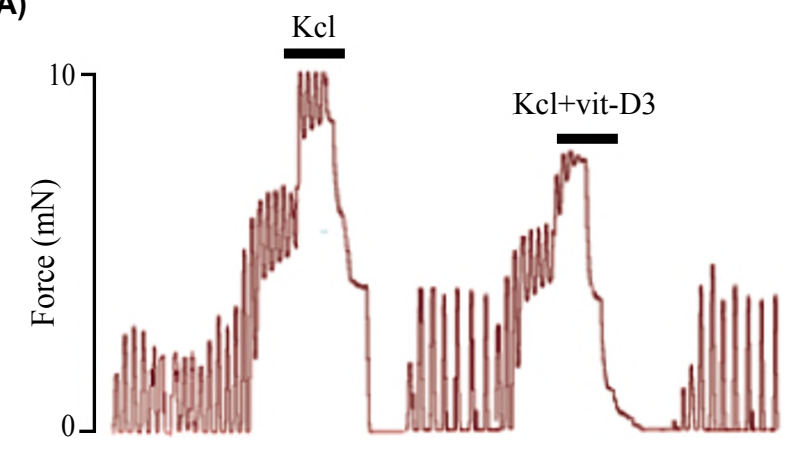

(B)

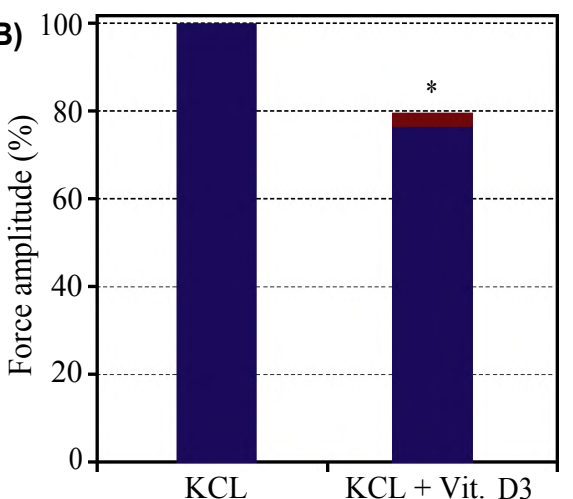

Fig. (2): The effect of vitamin $\mathrm{D} 3$ on rat uterine contractions in the presence of $\mathrm{KCl}$ solution. (A) Response of uterine strip to $60 \mathrm{mM}$ of $\mathrm{KCl}$ in the absence and presence of vitamin $\mathrm{D} 3\left(10^{-6} \mathrm{M}\right)$. (B) Bar chart showing the significant decrease in $\%$ force amplitude after vitamin D 3 treatment (mean \pm SEM). Control: $\mathrm{KCl}$ alone, ${ }^{*} p<0.05$.

(A)

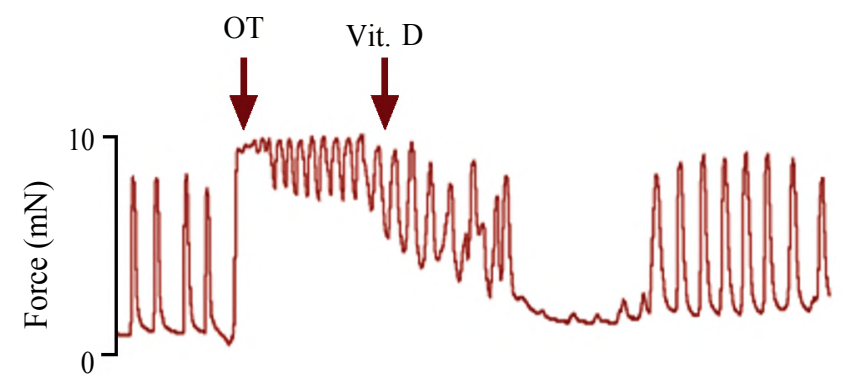

(B)

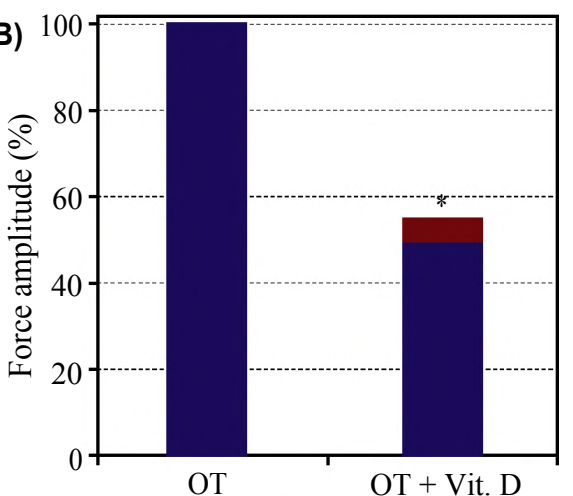

Fig. (3): The effect of vitamin D 3 on oxytocin (OT)-induced rat uterine contractions. (A) Recording of uterine contractions induced by $10-2 \mathrm{IU} / \mathrm{ml}$ OT and after the application of vitamin D $3\left(10^{-6} \mathrm{M}\right)$. (B) Bar charts showing a significant decrease in $\%$ force amplitude after vitamin D3 treatment (mean \pm SEM), Control: OT alone; $n=10$ independent samples $p<0.001$. 
(A)

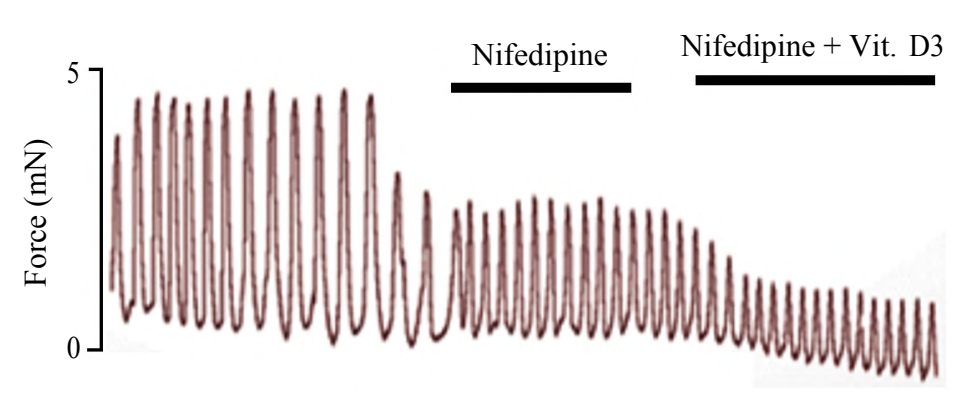

(B)

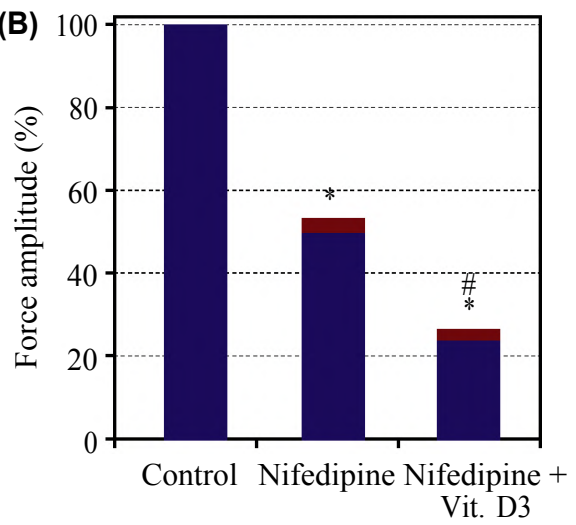

Fig. (4): The effect of vitamin D 3 on rat uterine contractions in the presence of nifedipine. (A) Response of uterine strip to nifedipine in the absence and presence of vitamin D $3\left(10^{-6} \mathrm{M}\right)$. (B) Bar chart showing the significant decrease in \% force amplitude after vitamin D 3 treatment (mean \pm SEM). Control: spontaneous contraction; *Significant to control, \#Significant to nifedipine alone.

\section{Discussion}

Vitamin D has a crucial role in reproductive function and health in the human and animal. In addition, VDR is expressed in the ovary, endometrium and myometrium [19]. However, the available data on the impact of vitamin D on the uterine function is limited. The role of vitamin D 3-VDR system in the rat uterus is interesting and worth to be investigated. Our obtained findings indicate that the rat uterus is a target tissue for vitamin $\mathrm{D} 3$, which should be considered as a locally acting regulator of uterine physiology. The present study show for the first time the influence of vitamin D 3 on rat myometrial strips in vitro. The main finding is that vitamin D 3 reversibly inhibits spontaneous periodic uterine contraction in a concentration dependent manner. Whether spontaneously initiated or oxytocin and $\mathrm{KCl}$-induced. The current findings are consistent with the previous study performed on smooth muscles of rat aorta [20], where significant decreases in endothelium-dependent contractions were observed after vitamin D 3 application by reducing the increase in cytosolic-free calcium concentration in the endothelial cells helping to explain the link between vitamin D deficiency and hypertension. The relaxing effect of vitamin $\mathrm{D} 3$ is dose-dependent and detected in all types of uterine contractions with or without endometrium, suggesting that it may directly or indirectly act to inhibit calcium channels or reduce intracellular calcium $\left[\mathrm{Ca}^{2}+\right]$, hence inhibiting contractions $[21,22]$. We also observed that vitamin D 3 inhibited oxytocin-induced periodic uterine contraction and high $\mathrm{K}^{+}$-induced tonic contraction. These results suggest that the inhibitory effect of vitamin D 3 could be operated by the prevention of mechanisms for spontaneous, oxytocin-induced periodic uterine contraction and high $\mathrm{K}+$-induced tonic contraction. Physiologically, extracellular $\mathrm{Ca}^{2}+$ enters the myocyte via the voltage-gated dihydropyridine channels located at the plasma membrane [23]. Then, it enters down its concentration gradient initiating the release of $\mathrm{Ca}^{2+}$ from the intracellular stores [24]. Uterine contractions induced by oxytocin is caused by increasing $\left[\mathrm{Ca}^{2}\right]$ i via calcium release from the sarcoplasmic reticulum and/or calcium influx via L-type $\mathrm{Ca}^{2+}$ channels [25]. Moreover, oxytocin is the chief pathway linked to the onset of preterm labor among the physiological pathways. Oxytocin binds to its $\mathrm{G}$ protein-coupled receptor, phospholipase C (PLC) is activated resulting in increased inositol trisphosphate (IP3) and diacylglycerol (DAG) levels. At the sarcoplasmic reticulum membrane, IP3 stimulates the IP3R receptor leading to $\mathrm{Ca}^{2}{ }^{+}$release from the stores into the cytosol. Elevated cytosolic $\mathrm{Ca}^{2}+$ further encouraged extracellular $\mathrm{Ca}^{2+}$ influx [26], hence a further rise in the intracellular $\mathrm{Ca}^{2} . \mathrm{Ca}^{2}+$ binds to calmodulin stimulating the myosin light chain kinase resulting in myosin light chains phosphorylation, promoting contraction [27].

Vitamin D3 significantly reduced the oxytocin effect on uterine muscle, this suggest the probable relaxant mechanism/s of vitamin D 3 . These results are supported by the findings of Wong et al., [20] who showed that that vitamin $\mathrm{D} 3$ reduces the vascular tone of the aorta of hypertensive rat by reducing calcium influx into the endothelial cells and hence decreasing the production of endothelium-derived contracting factors. However, Thota et al., demonstrated that vitamin D treatment decreased inflammation induced cytokines and contractile associated factors in the uterine myometrial smooth muscle cells via NF $\kappa B$ pathway [28]. 
In addition, vitamin D 3 significantly attenuated the tonic contraction induced by concentrated $\mathrm{KCl}$. Concentrated $\mathrm{KCl}$ solution induces depolarization, opening of L-type $\mathrm{Ca}^{2}+$ channels, and increasing the intracellular $\mathrm{Ca}^{2+}$ resulting in maintained uterine tonic contractions. $\mathrm{KCl}$-induced contraction can be attenuated by Rho A (a small GTPase protein) inhibitors in uterine smooth muscle [29], suggesting that depolarization by $\mathrm{KCl}$ could also activate ROCK (Rho associated protein kinase), which is serine kinase that determine the calcium sensitivity in smooth muscle cells and contribute to the regulation of smooth muscle contraction [30]. Therefore, the inhibitory effect of vitamin D 3 on KCl-induced contraction can be partially attributed to the direct blockade of L-type $\mathrm{Ca}^{2+}$ channels or through inhibition of ROCK pathways.

Administration of nifedipine, a dihydropyridine L-type $\mathrm{Ca}^{2}+$ channel antagonist, is an effective smooth muscle relaxant, resulted in a significant decline in the force amplitude of spontaneous uterine contractions. These findings are in accordance with the results of Lovasz et al., [31]. This contractility study revealed that the relaxant effect of nifedipine on spontaneous uterine contractions was significantly increased by the vitamin D 3 application suggesting that vitamin $\mathrm{D} 3$ depends not only on inhibition of extracellular $\mathrm{Ca}^{2+}$ influx in induction of uterine relaxation but another possible mechanism regulating intracellular $\mathrm{Ca}^{2}+$, The synergy of nifedipine with vitamin D 3 may be of novel therapeutic significance in the management of unwanted uterine contractions.

\section{Conclusion:}

Collectively, these data, for the first time, suggest that the in vitro administration of vitamin $\mathrm{D} 3$ inhibits the spontaneous uterine contractions; $\mathrm{KCl}$ induced uterine contraction and oxytocin-induced uterine contraction. This significant relaxing effect of vitamin $\mathrm{D} 3$ on the uterine contractility may be due to its inhibitory effect on L-type calcium channels in addition to inhibition of calcium release within the uterine smooth muscle. Therefore, vitamin D3 may be used as a novel approach in the relief of painful uterine contractions during dysmenorrhea or in the avoidance of the unwanted uterine contractions in early pregnancy that that involve the risk of miscarriage or preterm labor.

Using isolated uteri of rats, this in-vitro study offered preliminary proof that might be used to further evaluate the in vivo influence of vitamin D3 on human and animal uterine contractility. Further studies are needed to investigate the effect of vitamin $\mathrm{D} 3$ on human uterus, opening a new window for management of some gynecological disorders. It is also of great interest to further investigate the possible molecular mechanisms of vitamin D3, such as its physiological effect on ROCK activity, prostaglandin biosynthesis, and other calcium or potassium channels.

\section{Declaration of interest statement:}

The authors declare that there is no conflict of interests regarding the publication of this paper.

\section{Acknowledgment:}

The authors are grateful to the members of Zagazig Scientific and Medical Research Center (ZSMRC) in Zagazig University and Physiology Departments, Egypt for its support.

\section{References}

1- DARIOS E.S., SEITZ B. and WATTS S.W.: Smooth muscle pharmacology in the isolated virgin and pregnant rat uterus and cervix. J. Pharmacol. Exp. Ther., 341 (3): 587-96. doi: 10.1124/jpet.111.191031. [PubMed: 22366660]. 2012.

2- FUCHS A.R., BEHRENS O., MASCHEK H., KUPSCH E. and EINSPANIER A.: Oxytocinand vasopressin receptors in human and uterine myomas during menstrual cycle and early pregnancy. Hum. Reprod Update, 4 (5): 594604. doi: 10.1093/humupd/4.5.594. [PubMed: 10027613]. 1998.

3- GOLDENBERG R.L.: The management of preterm labor. Obstet. Gynecol., 100 (5 Pt 1): 1020-37. doi: 10.1097/ 00006250-200211000-00033. [PubMed: 12423 870]. 2002.

4- GOLDENBERG R.L., HAUTH J.C. and ANDREWS W.W.: Intrauterine infection and preterm delivery. N. Engl. J. Med., 342 (20): 1500-7. doi: 10.1056/NEJM 200005183422007. [PubMed: 10816189]. 2000.

5- GIMPL G. and FAHRENHOLZ F.: The oxytocin receptor system: Structure, function, and regulation. Physiol. Rev., 81 (2): 629-83. doi: 10.1152/physrev..81.2.629. [PubMed: 11274341]. 2001.

6- HOLICK M.F.: The role of vitamin D for bone health and fracture prevention. Curr. Osteoporos. Rep., 4 (3): 96e102, 2006.

7- LERCHBAUM E., OBERMAYER-PIETSCH B.; Vitamin D and fertility: A systematic review. Eur. J. Endocrinol., 166 (5): 765e78, 2012.

8- MALGORZATA GRZESIAK, EWA WASZKIEWICZ, MAGDALENA WOJTAS, KINGA KOWALIK and AN ITA FRANCZAK: Expression of vitamin D receptor in the porcine uterus and effect of $1,25(\mathrm{OH}) 2 \mathrm{D} 3$ on progesterone and estradiol-17b secretion by uterine tissues in vitro Theriogenology 125: 102-108, https://doi.org/ 10.1016/j.theriogenology.2018.10.026, 2019.

9- LUK J., TORREALDAY S., NEAL PERRY G. and PAL L.: Relevance of vitamin D in reproduction. Hum. Reprod, 27 (10): 3015e27, 2012.

10- DU H., DAFTARY G.S., LALWANI S.I. and TAYLOR H.S.: Direct regulation of HOXA10 by $1,25(\mathrm{OH}) 2 \mathrm{D} 3$ 
in human myelomonocytic cells and human endometrial stromal cells. Mol. Endocrinol., 19: 2222-2233, 2005.

11- DABROWSKI F.A., GRZECHOCINSKA B. and WIELGOS M.: The role of vitamin D in reproductive healtha trojan horse or the golden fleece? Nutrients, 7 (6): $4139 \mathrm{e} 53,2015$.

12- SHAHROKHI S.Z., GHAFFARI F. and KAZEROUNI F.: Role of vitamin D in female reproduction. Clin. Chim. Acta., 455: 33e8, 2016.

13- MUSCOGIURI G., ALTIERI B., de ANGELIS C., PALOMBA S., PIVONELLO R., COLAO A. and ORIO F. Shedding new light on female fertility: The role of vitamin D. Rev. Endocr. Metab. Disord, 18 (3): 273e83, 2017.

14- WRAY S. and NOBLE K.: Sex hormones and excitationcontraction coupling in the uterus: The effects of oestrous and hormones. J. Neuroendocrinol., 20 (4): 451-61, 2008.

15- BEK T., OTTESEN B. and FAHRENKRUG J.: The effect of galanin, CGRP and ANP on spontaneous smooth muscle activity of rat uterus. Peptides, 9: 497-500, 1988

16-MOHAMMED ALOTAIBI: The effect of cinnamon extract on isolated rat uterine strips. Reproductive biology 16 , (2 7-3 3. http://dx.doi.org/10.1016/j.repbio.2015.12.001 2016.

17- ALOTAIBI M., ARROWSMITH S. and WRAY S.: Hypoxia-induced force increase (HIFI) is a novel mechanism underlying the strengthening of labor contractions, produced by hypoxic stresses. Proc. Natl. Acad. Sci. USA, 112 (31): 9763-8, 2015.

18- NOBLE K. and WRAY S.: The role of the sarcoplasmic reticulum in neonatal uterine smooth muscle: Enhanced role compared to adult rat. J. Physiol., 545 (2): 557-66, 2002.

19- GRETA CHIARA CERMISONI, ALESSANDRA ALTERI, LAURA CORTI, ELISA RABELLOTTI, ENRICO PAPALEO, PAOLA VIGANÒ and ANA MARIA SANCHEZ: Vitamin D and Endometrium: A Systematic Review of a Neglected Area of Research. Int. J. Mol. Sci., 19, 2320; doi: 10.3390/ijms19082320, 2018.

20- MICHAEL S.K. WONG1 R. DELANSORNE2 RICKY Y.K. MAN1 and PAUL M.: Vanhoutte1 Vitamin D derivatives acutely reduce endothelium-dependent contractions in the aorta of the spontaneously hypertensive rat Am $\mathbf{J}$ Physiol Heart Circ. Physiol., 295: H289-H296, doi: 10. 1152/ajpheart.00 116, 2008.

21- ALVAREZ-COLLAZO J., ALONSO-CARBAJO L., LÓPEZ-MEDINA A.I., ALPIZAR Y.A., TAJADA S. NILIUS B., et al.: Cinnamaldehyde inhibits L-type calcium channels in mouse ventricular cardiomyocytes and vascular smooth muscle cells. Pflugers Arch. EJP, 466 (11): 208999, 2014.
22- XUE Y.L., SHI H.X., MURAD F. and BIAN K.: Vasodilatory effects of cinnamaldehyde and its mechanism of action in the rat aorta. Vasc. Health Risk Manag, 7 (1): 273-80, 2011.

23- CRESCENZO V.D., FOGARTY K.E., ZHUGE R., TUFT R.A., LIFSHITZ L.M., CARMICHAEL J., BELLVE K.D., BAKER S.P., ZISSIMOPOULOS S., LAI F.A., LEMOSAND J.R. and WALSH J.V.: Dihydropyridine receptors and type I ryanodine receptors constitute the molecular machinery for voltage-induced $\mathrm{Ca} 2+$ release in nerve terminals. J. Neurosci., 26 (29): 7565-7574, 2006.

24- AWUMEY E.M. and BUKOSKI R.D.: Cellular functions and fluxes of calcium. In Calcium in Human Health. Edited by Weaver C.M., Heaney R.P. Totowa, NJ: Humana Press Inc., 13-35, 2006.

25- PEREIRA-de-MORAIS L.1, SILVA A.A.2, da SILVA R.E.R.3, COSTA R.H.S.D.4, MONTEIRO Á.B.5, BARBOSA C.R.D.S.6, AMORIM T.S.7, de MENEZES IRA8, KERNTOPF M.R.9 and BARBOSA R.: Tocolytic activity of the Lippia alba essential oil and its major constituents, citral and limonene, on the isolated uterus of rats. Chem. Biol. Interact., 5; 297 :155-159, doi: 10.1016/j.cbi. 2018.11.006. Epub 2018 Nov 14. PMID: 30447181, 2019.

26- SHMYGOL A., GULLAM J., BLANKS A. and THORNTON S.: Multiple mechanisms involved in oxytocininduced modulation of myometrial contractility. Acta. Pharmacol. Sin, 27 (7): 827-832, 2006.

27- ARTHUR P., TAGGART M.J. and MITCHELL B.F.: Oxytocin and parturition: A role for increased myometrial calcium and calcium sensitization? Front Biosci, 12: 619633, 2007

28- CHANDRASEKHAR THOTA, ARCHANA LAKNAUR, TAKEISHA FARMER, GWINNETT LADSON, AYMAN AL-HENDY and NAHED ISMAIL: Vitamin D regulates contractile Profile in Human uterine myometrial Cells via NF_B pathway. Am. J. Obstet. Gynecol., 347.e1347.e10. doi:10.1016/j.ajog.2013.11.027, 2014.

29- KUPITTAYANANT S., BURDYGA T. and WRAY S. : The effects of inhibiting Rho-associated kinase with Y27632 on force and intracellular calcium in human myometrium. Pflügers Archiv, 443 (1): 112-4, 2001.

30- BOBBY MATHEW and SATYAN LAKSHMINRUSIMHA: Pathophysiology of Persistent Pulmonary Hypertension of the Newborn-Cellular Basis and Lessons from Animal Studies. Hemodynamics and Cardiology (Third Edition), 2019.

31- LOVASZ N., DUCZA E., ZUPKO I. and FALKAY G.: Increase of the uterus-relaxant effect of nifedipine by the Abcg2 efflux protein inhibitor KO134 in the rat in vivo. In Vivo, 27 (3): 363-9 PMID:23606692, 2013. 


\section{تأثير فيتامين دم على استجابة تقلص الرحم الهعزول للفئران}

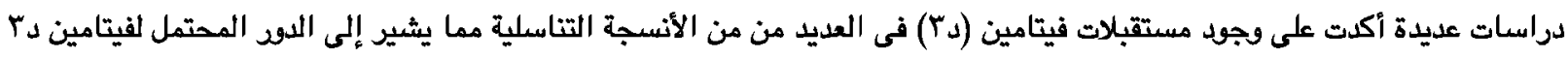

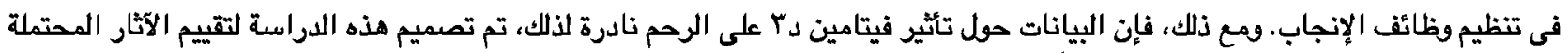

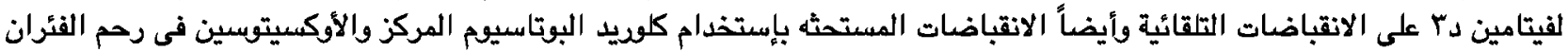
المعزفل فى المختبر.

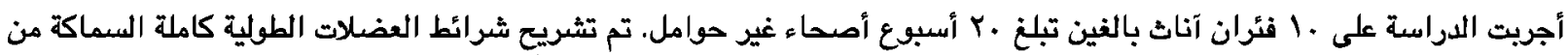

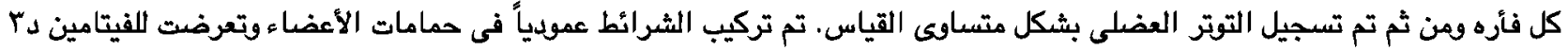

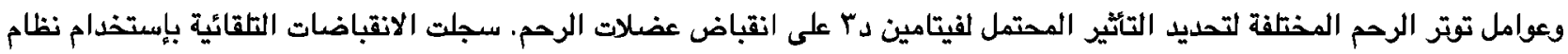

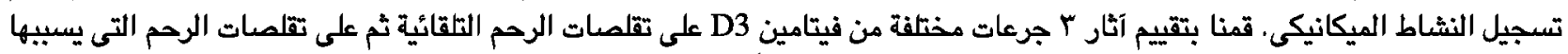

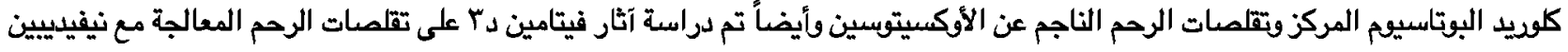
وهو بواء مضاد لبوابات الكالسيوم فى جدار الرحم: الرحم.

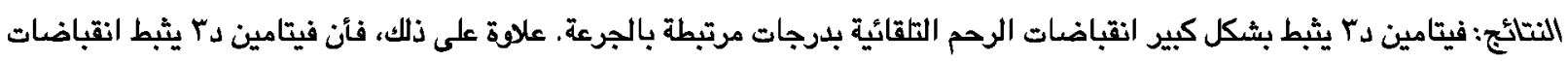

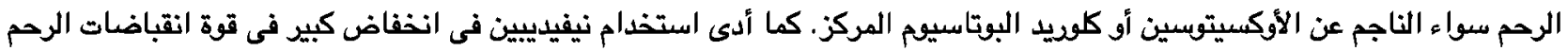

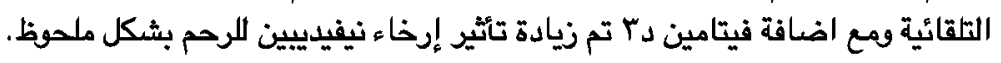

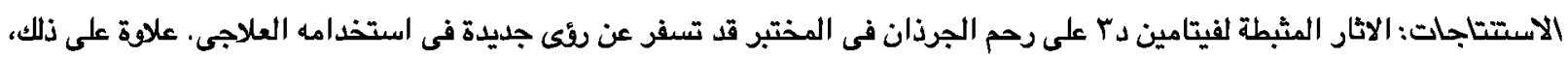

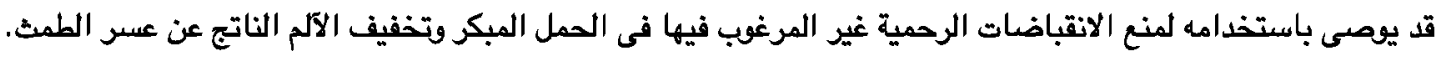

